\title{
Evaluation of the Influence of Fossil Fuel on Corrosion Resistance of Brass
}

\author{
Olayide Rasaq Adetunji*, Peter Olaitan Aiyedun, Sidikat Ibiyemi Kuye, \\ Dauda Adewale Lateef \\ Mechanical Engineering Department, Federal University of Agriculture, Abeokuta, Nigeria \\ Email: ${ }^{*}$ adetunjiolayide@gmail.com
}

Received 7 January 2014; revised 13 February 2014; accepted 28 February 2014

Copyright (C) 2014 by authors and Scientific Research Publishing Inc.

This work is licensed under the Creative Commons Attribution International License (CC BY). http://creativecommons.org/licenses/by/4.0/

c) (i) Open Access

\begin{abstract}
Brass is an excellent material choice for use in most industrial and agricultural application. Brass offers much better thermal conductivity and corrosion resistance than carbon or even stainless steel. Brass is an excellent material for use in both hot and cold water industrial and residential system including those carrying portable water. This study was carried out to investigate and evaluate the influence of fossil fuel like petrol, kerosene and diesel on the corrosion performance of brass. The samples were prepared for the study by cutting brass into $1 \mathrm{~cm}^{2}$ coupons and soaking them in different small plastic containers containing petrol, kerosene and diesel. The corrosion rate of each sample for a specific period of immersion $(120,240,360$, and 480,600 and 720 hours) was determined on average of three samples exposed under the same condition and test media in different container. The finding showed that brass is resistant to corrosion after long hours of contact in chosen liquid fossil fuels. Brass has the highest corrosion rate in petrol, followed by kerosene and least in diesel. The photomicrographs of the samples after ten days of immersion also confirmed this.
\end{abstract}

\section{Keywords}

Corrosion Performance, Brass, Petrol, Diesel and Kerosene

\section{Introduction}

The most common brass is nominal brass which contains $70 \%$ copper and $30 \%$ zinc. It is also known as "cartridge brass" this brass is subjected to dezincification if left for long times in water, the zinc disappears and the metal has a dull copper color as copper is all that is left on the surface. Brass with less than $15 \%$ zinc is sup-

*Corresponding author.

How to cite this paper: Adetunji, O.R., et al. (2014) Evaluation of the Influence of Fossil Fuel on Corrosion Resistance of Brass. Journal of Minerals and Materials Characterization and Engineering, 2, 176-181.

http://dx.doi.org/10.4236/jmmce.2014.23022 
posed not to dezincify in water. Brass should not be used in ammonia or nitrogen compound because of corrosive product form by brass in this environment and when it comes to machining, brass is much easier to cut than most ferrous materials. Brass is an excellent material choice for use in most industrial and agricultural application. Brass offers much better thermal conductivity and corrosion resistance than carbon or even stainless steel. Brass is an excellent material for use in both hot and cold water industrial and residential system including those carry portable water. Brass provides excellent resistance to corrosion in contact with petroleum products. Brass can be nickel plated to further reduce tarnishing and corrosion or to simply provide a silver finish. Nickel finishes may also be useful if a hard wear surface is required. Some examples of applications that are nickel plated for these purposes are door knobs, plumbing fixtures, gears and bearings [1].

Pure copper is a reddish, highly malleable metal, and was one of the first to be found and utilized. Copper and its alloys are widely used because of their excellent electrical, thermal conductivities, outstanding resistance to corrosion, ease fabrication and broad ranges of obtainable strength and special properties. Copper and copper alloys comprise one of the broadest and most versatile groups of engineering materials. Almost 500 copper alloys are currently recognized and are classified under international standard. Copper alloys are produced in all common forms. Choosing the correct alloy is simplified by the fact that copper metals are normally chosen for particular physical or mechanical properties and alloys with the desired properties can easily be sorted out [2]. The main reason why copper and its alloys are so widely used is that they offer a better combination of useful properties that cannot be found in other material. Brass possesses a number of properties that make it extreme useful in engineering material. The stability of metal or alloy in medium and corrosion resistance will depend on the protective properties and the properties of elements that make up the alloy. The properties include chemical composition, solubility, conductivity, adhesion, hygroscopicity and morphology determine the ability and control barrier to various kinds of attack and corrosion rate [3].

However this properties depend on the chemical composition and metallurgical history of the metal, physiochemical properties of coasting, and on environment variables such as atmospheric conditions, type of amount of contacted media, wet-dry cycles etc. [4].

The resistance of copper and its alloys has being attributed to protective cuprous oxide $\mathrm{Cu}_{2} \mathrm{O}$ layer formed upon exposure. However this alloy can deteriorate due to the formation of biofilm, whose polymeric structure allows local gradient of $\mathrm{pH}$ and $\mathrm{O}_{2}$. Selective dissolution of brass at various potentials and chlorine concentrations enhanced the conclusion that chlorine promotes the dissolution of copper and zinc [5]-[7].

Experiment has shown that corrosion rate is decided by factors such as temperature and dissolved oxygen concentration. The corrosion rate decreased steadily up to the ninth month exposure and decrease of corrosion rate is related to the protective film formed almost on brass panel and increase corrosion rate experienced by the brass is attributed to the removal of protective film by turbulence caused through influx of rain water and soft fouler and micro and micro algae exposure. The deterioration of machine parts coupled with contamination of environment with petroleum product thereafter is common in oil and gas industry. This research work ventured into development of durable and cost effective material for storage and transportation of petroleum products. The specific objective is to evaluate the influence of liquid petrol, kerosene and diesel on the corrosion performance of brass.

\section{Materials and Method}

Materials: Brass, petrol, kerosene, diesel, plastic containers, distilled water, paper tape, mentholated spirit and plastic bowls.

Apparatus: pH meter, sensitive weighing balance, bench shearing machine, steel rule and scriber and Optical Microscope.

Method: The samples were cut into coupons of 36 pieces using shearing machine and arc saw. The plastic containers were first washed with detergent, rinsed in distilled water and allowed to dry for hours. They were filled with testing fluids which were petrol, kerosene and diesel. Each of the measured samples was inserted into identified plastic containers. Complete immersion in testing fluid was ensured for periods of 120, 240, 360, 480, 600 and 720 hours. Proper cleaning of each sample was ensured after removal using water and mentholated spirit. After each period the samples were removed and weighed to determine the weight loss. The data were collected from the experiment and analyzed. Photomicrographs of samples after ten days of immersion were taken using Optical Microscope. The photomicrographs were done without etching to reveal the surface property at a magnification of 700 . 


\section{Results and Discussion}

Corrosion rates of brass in petrol, kerosene and diesel were low after long immersion period. Corrosion rate of brass in petrol was the highest, followed by brass in kerosene (both almost have the same pH of about 6.95 and a little increase from acidic to alkalis). Brass in diesel has the least corrosion rate and the $\mathrm{pH}$ was slightly less than that of kerosene and diesel which increase toward neutral. Diesel was most viscous among petrol and kerosene. This trend of corrosion rate is shown in Figure 1 and Tables 1-3. The corrosion rate of brass in petrol, kerosene and diesel were low after long period of contact. Corrosion rate was highest for brass in petrol than in kerosene, and the rate was least in diesel at early hours of immersion. The rate of corrosion was reduced for petrol, kerosene and diesel after thirty days of immersion as shown in Figure 1. The photomicrographs of brass sample and those immersed for ten days are displayed in Figures 2-5. Figure 2 shows light background $(\alpha)$ microstructure with little dark representing $(\beta)$ microstructure. The corrosive effects were shown in Figures 3-5 where more dark patches resulted from the attack.

Table 1. Corrosion performance of brass in petrol.

\begin{tabular}{ccccccc}
\hline Time [Hrs] & WI [g] & Wf $[\mathrm{g}]$ & Wd $[\mathrm{g}]$ & $\mathrm{Wl}\left[\mathrm{g} / \mathrm{m}^{2}\right]$ & $\mathrm{pH}$ & CR [mm/yr] \\
\hline 120 & 2.13 & 2.1847 & 0.0547 & 547 & 6.975 & 4.6648 \\
240 & 2.48 & 2.5283 & 0.0483 & 483 & 7.01 & 2.068 \\
360 & 1.84 & 1.851 & 0.011 & 110 & 7.03 & 0.3127 \\
480 & 2.29 & 2.3029 & 0.0129 & 129 & 7.055 & 0.275 \\
600 & 2.15 & 2.1572 & 0.00720 & 72 & 7.065 & 0.1228 \\
720 & 1.945 & 1.9506 & 0.0056 & 55.5 & 7.09 & 0.0789 \\
\hline
\end{tabular}

Area $=0.0001 \mathrm{~m}^{2}$.

Table 2. Corrosion performance of brass in kerozene.

\begin{tabular}{ccccccc}
\hline Time [Hrs] & Wi [g] & Wf [g] & Wd [g] & Wl [g/m $\left.{ }^{2}\right]$ & $\mathrm{pH}$ & $\mathrm{Cr}[\mathrm{mm} / \mathrm{yr}]$ \\
\hline 120 & 1.668 & 1.6991 & 0.0311 & 311 & 6.97 & 2.6522 \\
240 & 2.362 & 2.3895 & 0.0295 & 295 & 6.98 & 1.2579 \\
360 & 2.475 & 2.4825 & 0.0075 & 74.5 & 6.98 & 0.2118 \\
480 & 1.88 & 1.8901 & 0.0101 & 100.5 & 6.995 & 0.2143 \\
600 & 1.96 & 1.9697 & 0.0097 & 96 & 6.998 & 0.1646 \\
720 & 1.705 & 1.7102 & 0.0052 & 51.5 & 7.01 & 0.0739 \\
\hline
\end{tabular}

Area $=0.0001 \mathrm{~m}^{2}$.

Table 3. Corrosion performance of brass in diesel.

\begin{tabular}{ccccccc}
\hline Time & Wi [g] & Wf [g] & Wd [g] & Wl [g/m²] & pH & Cr [mm/yr] \\
\hline 120 & 2.35 & 2.3558 & 0.0058 & 58 & 5.55 & 0.4946 \\
240 & 2.435 & 2.4412 & 0.0062 & 62 & 5.75 & 0.2644 \\
360 & 1.88 & 1.8842 & 0.0042 & 42 & 6.00 & 0.1194 \\
480 & 1.845 & 1.8465 & 0.0015 & 15 & 6.025 & 0.03198 \\
600 & 1.64 & 1.6416 & 0.0016 & 16 & 6.025 & 0.0273 \\
720 & 1.695 & 1.6964 & 0.0014 & 14 & 6.025 & 0.0199 \\
\hline
\end{tabular}

Area $=0.0001 \mathrm{~m}^{2}$. 


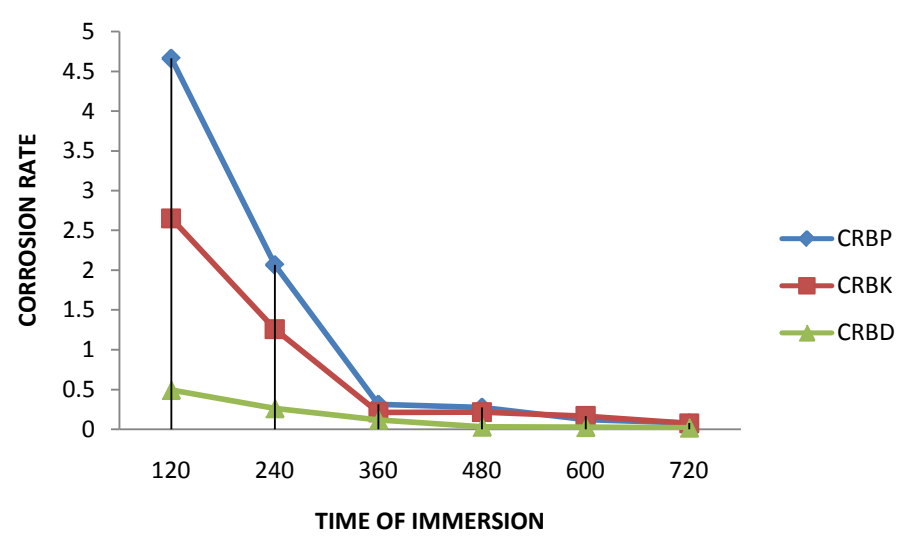

Figure 1. Corrosion Rate (mm/y) against time of immersion (hours) of Brass in Petrol, Kerosene and Diesel.

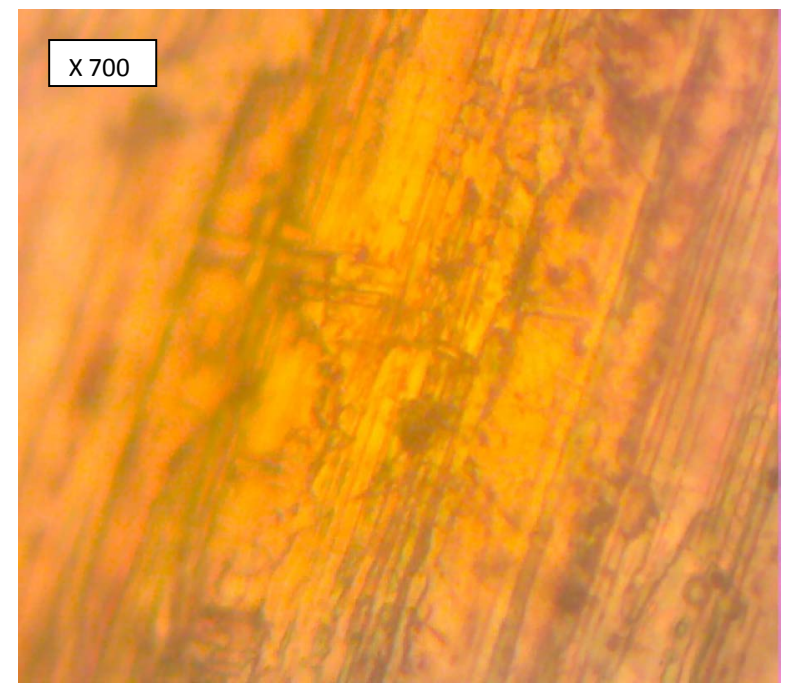

Figure 2. Photomicrograph of brass sample $\times 700$.

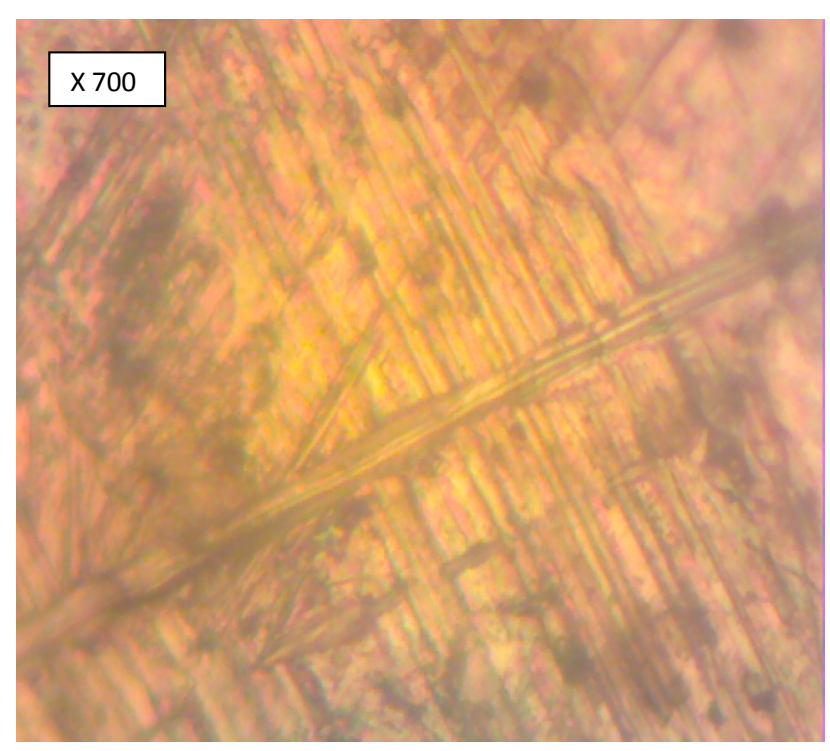

Figure 3 . Photomicrograph of brass in petrol for ten days $\times 700$. 


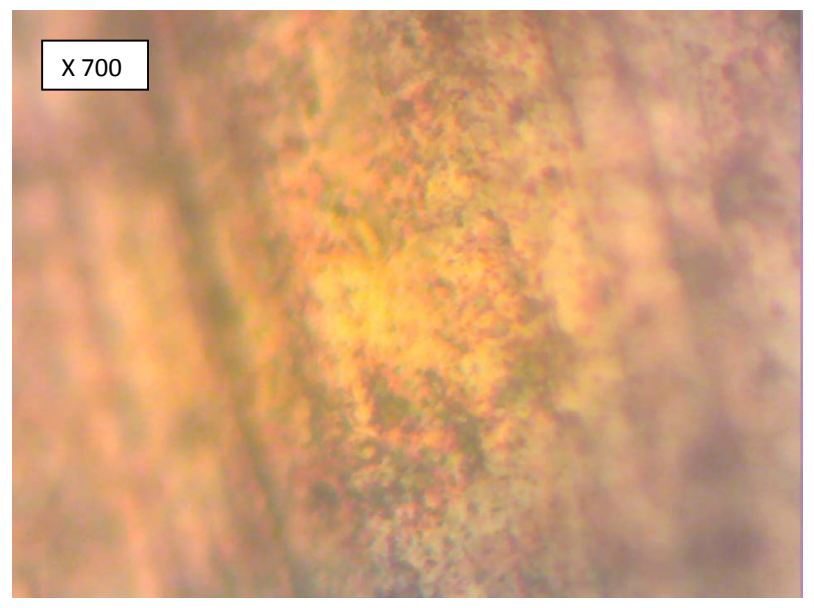

Figure 4. Photomicrograph of brass in diesel after 10 days immersion $\times 700$.

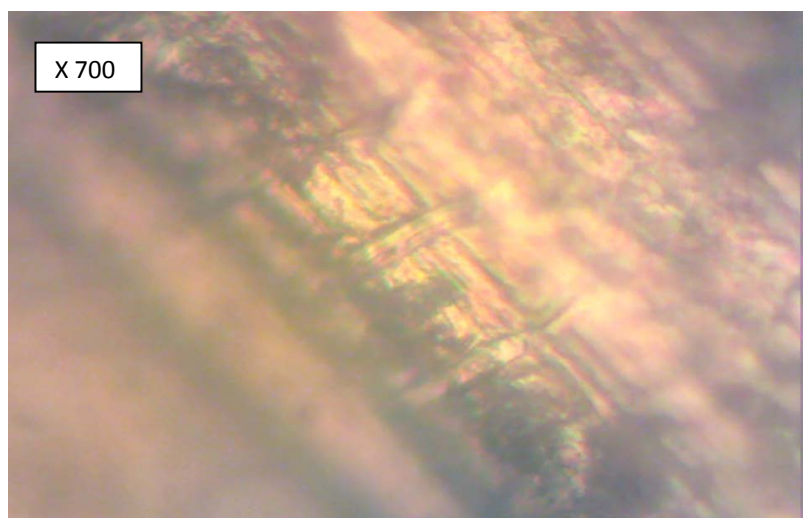

Figure 5. Photomicrograph of brass in kerosene after 10 days immersion $\times 700$.

Decrease in corrosion rate of brass may be due to formation of protective film such as cuprous oxide $\mathrm{Cu}_{2} \mathrm{O}$ on copper and its alloy which prevent further corrosion when further expose to the environment. The corrosion rate decreased steadily in brass due to the protective film form almost on brass panel. The corrosion of brass may continue due to removal of protective film from the surface as the oxygen in the petroleum product increase [8].

Petroleum product containing non hydrocarbon like organic sulfur, nitrogen and oxygen compounds and their presence as impurities can be harmful and fuel having high sulfur and nitrogen levels cause pollution problems in addition to the corrosive nature of their oxidation products. For petroleum containing nitrogen or nitrogen compound [ammonia] should not be used in brass environment because zinc dissociates from copper [dezincification] and the metal has a dull copper color [9] [10].

\section{Conclusion}

In conclusion, the influence of liquid petroleum products on the corrosion rate of brass was investigated and the following findings were deduced from the study.

- The corrosion rates of brass in petrol, kerosene and diesel were low after a long period of contact.

- Corrosion rate was highest for brass in petrol than in kerosene, and the rate was least in diesel at early hours of immersion.

\section{References}

[1] Friel, J.J. and Townsend, H.E. (1983) Corrosion Resistance of Zinc and Zinc-Aluminium Alloy Coatings. Sheet Metal 
Industries, 60, 506-507.

[2] Goodwin, F.E. (1990) Zinc Base Steel Coating Systems: Metallurgy and Performance. In: Krauss, G., Ed., The Minerals, Metals and Materials Society.

[3] Bockris, J.O.M., Reddy, A.K.N. and Gamboa-Aldeco, M. (2000) Modern Electrochemistry. 2nd Edition, Kluwer Academic, Norwell.

[4] Cabrera-Sierra, R., García, I., Sosa, E., Oropeza, T. and González, I. (2000) Electrochemical Behavior of Carbon Steel in Alkaline sour Environments Measured by Electrochemical Impedance Spectroscopy. Electrochimica Acta, 46, 487497. http://dx.doi.org/10.1016/S0013-4686(00)00567-3

[5] Stratmann, S.G. and Streckel, H. (1990) On the Atmospheric Corrosion of Metals Which Are Covered with Thin Electrolyte Layers. II. Experimental Results. Corrosion Science, 30, 697-714. http://dx.doi.org/10.1016/0010-938X(90)90033-2

[6] Townsend, H.E. and Fisher, T.W. (1982) Al-Zn Alloy Coated Steel Sheet and Wire, Metals Hand Book. 9th Edition, Cleaning, Finishing and Coating, Vol. 5, American Society for Metals, Metals Park, 646-649.

[7] Hamdy, A.S., Sa'eh, A., Shoeib, M.A. and Barakat, Y. (2007) Evaluation of Corrosion and Erosion Corrosion Resistance of Mild Steel in Sulfide Polluted NaCl Solution. Presented at the European Corrosion Congress, EuroCorr, Germany.

[8] Kharafi, F.M. (2008) Electrochemistry. Solid State Letter, 11, G15-G18. http://dx.doi.org/10.1149/1.2832428

[9] Jekayinfa, S.O., Waheed, M.A., Adebiyi, K.A. and Adebiyi, F.T. (2005) Effect Cassava Fluid on Corrosion Performance of Mild Steel. Ant-Corrosion Methods and Materials, Emerald Group Publishing Limited, Vol. 50.

[10] Lawal, G.I., Amuda, M.O.H. and Fasuba, D.A. (2006) Inhibitive Behaviour of Tobacco Extract on Corrosion of Mild Steel in Acidic and Salty Media. NSE Technical Transaction, 41. 